\title{
Bone Mineral Density Trends During the First Year After Laparoscopic Sleeve Gastrectomy-a Cohort Study on 241 Patients
}

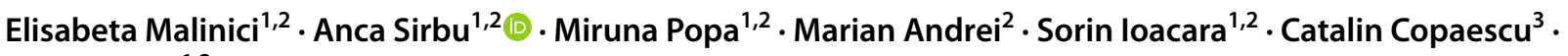 \\ Simona Fica ${ }^{1,2}$
}

Received: 10 June 2021 / Revised: 5 August 2021 / Accepted: 11 August 2021 / Published online: 27 August 2021

(c) The Author(s) 2021

\begin{abstract}
Purpose Laparoscopic sleeve gastrectomy (LSG) is an effective weight loss procedure, but detrimental effects on bone health have been described. We aimed to assess the dynamics of regional and total bone mineral density (BMD) in a cohort of patients undergoing LSG and to capture gender differences in terms of evolution.

Materials and Methods We conducted a retrospective study on 241 patients who underwent LSG to determine the regional and total BMD changes at 6 and 12 months after the intervention.

Results One hundred ten males and 140 females ( 97 pre-, 43 postmenopausal) were included. Mean baseline body mass index (BMI) was $44.16 \pm 6.11 \mathrm{~kg} / \mathrm{m}^{2}$ in males and $41.60 \pm 5.54 \mathrm{~kg} / \mathrm{m}^{2}$ in females, reaching $28.62 \pm 4.26 \mathrm{~kg} / \mathrm{m}^{2}$ and $27.39 \pm 4.2 \mathrm{~kg} /$ $\mathrm{m}^{2}$, respectively, at 12 months. BMD showed a continuous decline, with significant loss from 6 months postoperatively. There was a positive correlation between BMD and BMI decline at 12 months $(r=0.134, p<0.05)$. Total BMD loss at 12 months was significantly greater in males than premenopausal females, independent of BMI variation and age. During the first 6 months, men lost significantly more bone mass than premenopausal and postmenopausal women (BMD variation was $2.62 \%, 0.27 \%, 1.58 \%$, respectively). The second period (6-12 months) was similar in all three groups, revealing a further steady $(\sim 1.4 \%)$ BMD decline.

Conclusions Our results are consistent with previous findings that LSG negatively impacts BMD, stressing the importance of bone health-oriented measures in postoperative care. Moreover, the impact that seems more significant in males warrants future exploration, as it might change clinical practice.
\end{abstract}

Keywords Obesity $\cdot$ Sleeve gastrectomy $\cdot$ Bone mineral density

Key points

- Bone mineral density decreases significantly in the first year

after sleeve gastrectomy.

- Men experience more profound bone loss compared to

premenopausal women.

- Bone loss in men occurs at an accelerated pace during the first 6

months postoperatively.

Anca Sirbu

ancaelenasirbu@yahoo.com; anca.sirbu@umfcd.ro

Elisabeta Malinici

drelisabetasava@yahoo.com

Miruna Popa

mirunamariapopa@gmail.com

Marian Andrei

marianandrei18@gmail.com

Sorin Ioacara

drsorin@yahoo.com
Catalin Copaescu

catalincopaescu@gmail.com

Simona Fica

simonafica55@gmail.com

1 Department of Endocrinology, Carol Davila University of Medicine and Pharmacy, Dionisie Lupu Street, no. 37, Sector 2, 020021 Bucharest, Romania

2 Elias University Emergency Hospital, Marasti bd, no 17, Sector 1, 011461 Bucharest, Romania

3 General Surgery Department, Ponderas Hospital, 85A Nicolae G Caramfil Street, Sector 1, 014142 Bucharest, Romania 


\section{Introduction}

Obesity is a major public health issue, with a global rise in prevalence that has reached pandemic proportions over the past decades [1, 2]. Paralleling these trends and aided by the evolution of laparoscopic techniques, bariatric surgery has also shown a significant expansion. The most commonly performed interventions are Roux-en-Y gastric bypass (RYGB) and laparoscopic sleeve gastrectomy (LSG), with the latter becoming increasingly popular in the past years [3, 4]. LSG has proven clear beneficial effects on weight loss (both short-term and sustained), as well as improvement of obesity-related morbidity and mortality [5-9]. However, a matter of concern is the impact of bariatric surgery on bone homeostasis [10,11]. Altered bone metabolism, accelerated bone loss, and increased fracture risk have been widely reported in patients undergoing RYGB [12-14], while data on the impact of LSG on bone health are limited $[15,16]$.

Dual-energy X-ray absorptiometry (DXA) scans are the most commonly performed investigations in clinical practice for bone mass assessment. Bone mineral density (BMD) has been long shown to correlate with fracture risk [17]. It is useful both as a diagnostic tool and for monitoring changes associated with either therapy or other detrimental factors $[18,19]$.

In this study, we aimed to assess the dynamics of regional and total BMD in a cohort of patients with obesity undergoing LSG, 6 and 12 months after the intervention, and to capture possible gender differences in terms of evolution.

\section{Materials and Methods}

\section{Study Population}

We conducted a retrospective study using prospectively collected data on a cohort of adult patients with obesity who underwent LSG at an International Federation for the Surgery of Obesity and Metabolic Disorders (IFSO) accredited Center of Excellence in Romania. The study was conducted with approval of the local Ethics Committee and following the ethical standards of the Helsinki Committee for Human Rights. Written informed consent was obtained from all patients.

Inclusion criteria were in accordance with guideline recommendations for bariatric surgery [20], while exclusion criteria consisted of age under 18 years old, use of medication impacting bone metabolism (other than calcium, vitamin D or hormonal contraception), known metabolic bone disease, and previous bariatric procedures. Three hundred forty patients met the inclusion criteria. Of them, 308 had complete baseline evaluation. Fifty-seven patients missed the 6 months follow-up visit, while another 29 missed the 12-month evaluation. The final analysis was performed on the 241 patients that had complete baseline and postoperative follow-up evaluation. All patients were provided professional nutritional and lifestyle recommendations, as advised by available guidelines at the time of intervention [20].

\section{Anthropometric Measurements}

At every visit, body weight, height, waist and hip circumference were measured. Body mass index (BMI) was calculated as weight (in kilograms) divided by the square of height. Excess weight loss percentage (EWL) was calculated as [(Preoperative BMI - current BMI)/(preoperative $\mathrm{BMI}-25)] \times 100$.

\section{Scan Procedure-Dual-Energy X-ray Absorptiometry (DXA)}

DXA scans were performed using Lunar iDXA Forma (GE Healthcare). Total body and regional values of BMD $\left(\mathrm{g} / \mathrm{cm}^{2}\right)$ were recorded. All scans were performed by an ISCD-certified DXA technologist and analyzed with the same software.

\section{Statistical Analysis}

Statistical analysis was performed using SPSS software, version 23.0. Quantitative variables were expressed as the mean \pm standard deviation (SD). Continuous variables were compared using Student $t$ test. Student paired $t$ test was used to analyze the statistical significance of parameter variations during follow-up. All analyses were 2-tailed, with $p<0.05$ considered statistically significant. Repeated Measures ANOVA test was used to assess time and gender effect for patients undergoing LSG. Effects were measured using Wilk's Lambda test using a significance level of 0.001. Univariate general linear model (GLM) has been used to determine the relationship between BMD variation after 12 months and gender (including menopausal status for women), adding \%BMI and age as covariates. Bonferroni post hoc test was applied for multiple comparisons.

\section{Results}

A total of 241 subjects ( 140 women $(58.1 \%)$ and 101 men (41.9\%)) were included. Age ranged from 19 to 67 years, with a mean of $41.66 \pm 10.99$ and no significant difference between genders. Mean baseline BMI was $44.16 \pm 6.11$ 
Table 1 Anthropometric characteristics at baseline, 6 and 12 months of follow-up, grouped by gender

\begin{tabular}{|c|c|c|c|c|c|c|c|c|}
\hline & \multicolumn{2}{|l|}{ Baseline } & \multicolumn{2}{|l|}{6 months } & \multicolumn{2}{|l|}{12 months } & \multicolumn{2}{|l|}{$\mathrm{p}^{2}$} \\
\hline & $\begin{array}{l}\text { Males } \\
(n=101)\end{array}$ & $\begin{array}{l}\text { Females } \\
(n=140)\end{array}$ & $\begin{array}{l}\text { Males } \\
(n=101)\end{array}$ & $\begin{array}{l}\text { Females } \\
(n=140)\end{array}$ & $\begin{array}{l}\text { Males } \\
(n=101)\end{array}$ & $\begin{array}{l}\text { Females } \\
(n=140)\end{array}$ & Time effect & $\begin{array}{l}\text { Time } x \\
\text { gender } \\
\text { effect }\end{array}$ \\
\hline BMI $\left(\mathrm{kg} / \mathrm{m}^{2}\right)$ & $44.16 \pm 6.11$ & $41.6 \pm 5.54$ & $31.32 \pm 4.69$ & $30.15 \pm 4.5$ & $28.62 \pm 4.26$ & $27.39 \pm 4.2$ & $<.001$ & $<.001$ \\
\hline Weight (kg) & $142.94 \pm 21.32$ & $114.71 \pm 15.49$ & $101.38 \pm 16.23$ & $83.11 \pm 12.44$ & $92.59 \pm 14.38$ & $75.52 \pm 11.86$ & $<.001$ & $<.001$ \\
\hline WHR & $1.06 \pm 0.08$ & $0.95 \pm 0.08$ & $1.01 \pm 0.07$ & $0.92 \pm 0.08$ & $0.97 \pm 0.08$ & $0.91 \pm 0.08$ & $<.001$ & $<.001$ \\
\hline $\mathrm{WC}(\mathrm{cm})$ & $139.82 \pm 14.67$ & $123.37 \pm 12.92$ & $110.84 \pm 12.14$ & $102.1 \pm 11.98$ & $102.97 \pm 11.93$ & $95.28 \pm 11.17$ & $<.001$ & $<.001$ \\
\hline $\mathrm{HC}(\mathrm{cm})$ & $132.32 \pm 13.12$ & $130.16 \pm 11.05$ & $110.17 \pm 10.09$ & $110.33 \pm 9.7$ & $105.67 \pm 8.62$ & $104.25 \pm 7.97$ & $<.001$ & NS \\
\hline
\end{tabular}

${ }^{1} B M I$ body mass index, $W H R$ waist-hip ratio, $W C$ waist circumference, $H C$ hip circumference

${ }^{2}$ Derived by using repeated measures ANOVA

${ }^{3}$ Values were expressed by Mean \pm SD

Table 2 Densitometric variables at baseline, 6 and 12 months of follow-up

\begin{tabular}{llll}
\hline & Baseline & 6 months & 12 months \\
\hline Head BMD $\left(\mathrm{g} / \mathrm{cm}^{2}\right)$ & $2.201 \pm 0.28$ & $2.190 \pm 0.27$ & $2.185 \pm 0.27^{* \mathrm{~b}}$ \\
Arms BMD $\left(\mathrm{g} / \mathrm{cm}^{2}\right)$ & $0.977 \pm 0.14$ & $0.937 \pm 0.15^{\mathrm{a}}$ & $0.926 \pm 0.14^{\mathrm{b}}$ \\
Legs BMD $\left(\mathrm{g} / \mathrm{cm}^{2}\right)$ & $1.344 \pm 0.15$ & $1.349 \pm 0.14$ & $1.328 \pm 0.14^{\mathrm{b}, \mathrm{c}}$ \\
Trunk BMD $\left(\mathrm{g} / \mathrm{cm}^{2}\right)$ & $1.117 \pm 0.11$ & $1.086 \pm 0.11^{\mathrm{a}}$ & $1.058 \pm 0.11^{\mathrm{b}, \mathrm{c}}$ \\
Ribs BMD $\left(\mathrm{g} / \mathrm{cm}^{2}\right)$ & $1.025 \mathrm{r} \pm 0.11$ & $0.960 \pm 0.09^{\mathrm{a}}$ & $0.924 \pm 0.10^{\mathrm{b}, \mathrm{c}}$ \\
Pelvis BMD $\left(\mathrm{g} / \mathrm{cm}^{2}\right)$ & $1.113 \pm 0.13$ & $1.105 \pm 0.13^{* \mathrm{a}}$ & $1.079 \pm 0.13^{\mathrm{b}, \mathrm{c}}$ \\
Spine BMD $\left(\mathrm{g} / \mathrm{cm}^{2}\right)$ & $1.277 \pm 0.15$ & $1.244 \pm 0.13^{\mathrm{a}}$ & $1.220 \pm 0.13^{\mathrm{b}, \mathrm{c}}$ \\
Total BMD $\left(\mathrm{g} / \mathrm{cm}^{2}\right)$ & $1.292 \pm 0.11$ & $1.272 \pm 0.11^{\mathrm{a}}$ & $1.254 \pm 0.11^{\mathrm{b}, \mathrm{c}}$ \\
\hline
\end{tabular}

$B M D$ bone mineral density; Values are represented as mean \pm standard deviation and are compared by Student's $t$ test for independent samples.

a $-p<0.0016$ months vs baseline

*a $p<0.056$ months vs baseline

b- $p<0.00112$ months vs baseline

*b $p<0.0512$ months vs baseline

${ }^{c}$ - $p<0.00112$ months vs 6 months

$\mathrm{kg} / \mathrm{m}^{2}$ in males and $41.60 \pm 5.54 \mathrm{~kg} / \mathrm{m}^{2}$ in females, decreasing to $28.62 \pm 4.26 \mathrm{~kg} / \mathrm{m}^{2}$ and $27.39 \pm 4.2 \mathrm{~kg} / \mathrm{m}^{2}$, respectively, 12 months postoperatively. The evolution of anthropometric parameters is presented in Table 1.

BMD decreased at almost all analyzed sites at 6 months post-LSG and continued to decline during the subsequent 6 months. Total BMD followed the same downward trend $\left(1.220 \mathrm{~g} / \mathrm{cm}^{2}\right.$ at 12 months vs $1.292 \mathrm{~g} / \mathrm{cm}^{2}$ at baseline, $p<0.001)$. An exception was leg BMD, which showed no decline at 6 months but did decrease at 12 months postoperatively $\left(1.328 \mathrm{~g} / \mathrm{cm}^{2}\right.$ vs $\left.1.344 \mathrm{~g} / \mathrm{cm}^{2}, p<0.001\right)$. BMD and BMI decline correlated positively at 12 months $(r=0.134$, $p<0.05)$. BMD decline and EWL showed no correlation. Results are summarized in Table 2.
Gender-oriented analysis revealed a more significant bone loss in males at almost all measured sites (including spinea loss of BMD of $5.67 \%$ vs $1.01 \%$ at 6 months, rising to $5.74 \%$ vs $3.16 \%$ at 12 months). Furthermore, we divided females according to menopausal status (premenopausal $N=97$, postmenopausal $N=43$ ). At 12 months post-LSG, men showed a significantly higher decline in total BMD than premenopausal women at all sites except the head (Table 3).

To eliminate the impact of confounding factors, we adjusted the analysis for age and BMI change. GLM confirmed a greater total BMD decline in men versus premenopausal women (mean difference $2.37 \%, p<0.05$ ). Conversely, the difference in BMD decline between men and postmenopausal women did not reach statistical significance. Analyzing total BMD trends over 12 months post-LSG using covariates model, differences in patterns of bone loss emerged. During the first 6 months post-LSG, men, premenopausal and postmenopausal women lost $2.62 \%, 0.27 \%$, and $1.58 \%$ of BMD, respectively. The second period of observation (6-12 months) is similar in all three groups, revealing steady BMD decline (an additional 1.4\% approximately) (Fig. 1).

\section{Discussion}

Our study aimed to evaluate the impact of LSG on BMD and compare gender-specific trends in post-surgical bone loss. Multiple studies have demonstrated decreased DXAevaluated BMD after bariatric surgery [21-23]. BMD decreased at almost all analyzed sites in our cohort-including spine at 6 months and continued to decline during the subsequent 6 months post-LSG. Published studies show inconsistent results regarding regional BMD evolution postbariatric surgery. A recent study by Ieong et al., including patients who underwent either RYGB or LSG, found that, after 24 months, all subjects had a significant decrease in the femoral neck, femoral trochanter, and total hip BMD; 
Table 3 Assessment of gender- and menopausal-related changes at 6 and 12 months of follow-up

\begin{tabular}{|c|c|c|c|c|c|c|}
\hline \multirow[t]{2}{*}{$\%$ change Variable } & \multicolumn{3}{|l|}{ After 6 months } & \multicolumn{3}{|l|}{ After 12 months } \\
\hline & $\begin{array}{l}\text { PreM W } \\
(n=97)\end{array}$ & $\begin{array}{l}\text { PostM W } \\
(n=43)\end{array}$ & $\begin{array}{l}\text { Men } \\
(n=101)\end{array}$ & $\begin{array}{l}\text { PreM W } \\
(n=97)\end{array}$ & $\begin{array}{l}\text { PostM W } \\
(n=43)\end{array}$ & $\begin{array}{l}\text { Men } \\
(n=101)\end{array}$ \\
\hline \multicolumn{7}{|c|}{ General characteristics changes (\%) } \\
\hline BMI & $28.49 \pm 4.39$ & $25.23 \pm 6.03^{c}$ & $28.94 \pm 5.77^{\mathrm{a}}$ & $35.51 \pm 6.27$ & $30.44 \pm 7.97^{\mathrm{c}}$ & $34.83 \pm 7.46^{\mathrm{a}}$ \\
\hline EWL & $77.28 \pm 23.01$ & $66.12 \pm 17.75^{\mathrm{c}}$ & $70.44 \pm 18.19$ & $95.32 \pm 25.18^{\mathrm{b}}$ & $79.40 \pm 22.07^{\mathrm{c}}$ & $84.08 \pm 19.89$ \\
\hline \multicolumn{7}{|c|}{ Bone mineral density changes (\%) } \\
\hline Head BMD & $0.43 \pm 2.39$ & $1.45 \pm 5.21$ & $-0.22 \pm 5.91$ & $0.71 \pm 2.91$ & $1.65 \pm 2.96$ & $-0.01 \pm 6.39$ \\
\hline Arms BMD & $1.77 \pm 17.37$ & $3.03 \pm 15.29$ & $3.71 \pm 17.07$ & $3.27 \pm 15.96$ & $3.32 \pm 13.12$ & $4.97 \pm 16.79$ \\
\hline Legs BMD & $-1.28 \pm 3.40$ & $-0.35 \pm 3.20$ & $0.23 \pm 2.94^{\mathrm{b}}$ & $0.13 \pm 3.42$ & $1.89 \pm 3.53^{\mathrm{c}}$ & $1.71 \pm 3.34^{\mathrm{b}}$ \\
\hline Trunk BMD & $1.40 \pm 3.07$ & $1.58 \pm 3.53$ & $4.42 \pm 3.37^{\mathrm{a}, \mathrm{b}}$ & $3.93 \pm 3.87$ & $4.06 \pm 5.14$ & $6.96 \pm 4.14^{\mathrm{a}, \mathrm{b}}$ \\
\hline Ribs BMD & $4.40 \pm 3.65$ & $4.87 \pm 4.65$ & $8.46 \pm 4.81^{\mathrm{a}, \mathrm{b}}$ & $7.52 \pm 5.91$ & $7.11 \pm 10.43$ & $12.67 \pm 5.75^{\mathrm{a}, \mathrm{b}}$ \\
\hline Pelvis BMD & $0.29 \pm 4.19$ & $-0.40 \pm 6.62$ & $1.19 \pm 5.17$ & $2.52 \pm 4.84$ & $2.84 \pm 7.04$ & $3.29 \pm 5.32$ \\
\hline Spine BMD & $0.64 \pm 5.53$ & $1.84 \pm 7.33$ & $5.67 \pm 7.45^{\mathrm{a}, \mathrm{b}}$ & $3.21 \pm 4.93$ & $3.06 \pm 5.65$ & $5.74 \pm 6.09^{\mathrm{a}, \mathrm{b}}$ \\
\hline Total BMD & $0.39 \pm 3.43$ & $1.06 \pm 2.72$ & $2.57 \pm 3.49^{\mathrm{a}, \mathrm{b}}$ & $1.76 \pm 3.51$ & $2.42 \pm 3.10$ & $4.04 \pm 3.27^{\mathrm{a}, \mathrm{b}}$ \\
\hline
\end{tabular}

PreM $W$ premenopausal women, Post $M W$ postmenopausal women; The $\%$ change was defined as $100 \mathrm{X}$ [measure 1-measure 2]/measure 1 .

a $-p<0.05$ when comparing men- postmenopausal women

$\mathrm{b}-p<0.05$ when comparing men- premenopausal women

${ }^{c}$ - $p<0.05$ when comparing postmenopausal women- premenopausal women

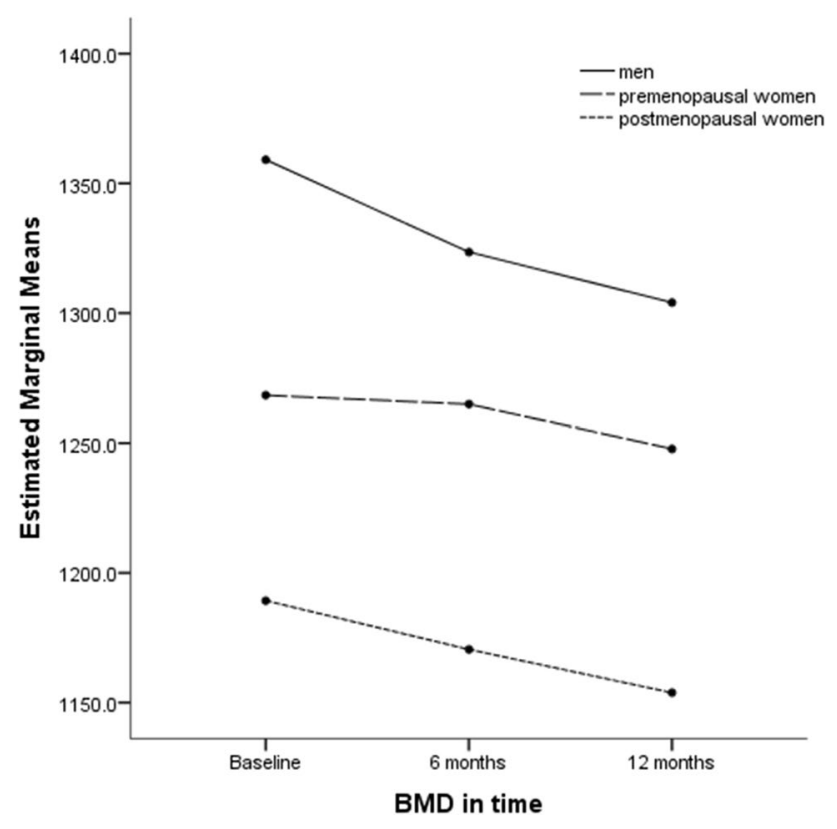

Fig. 1 Total BMD trends over 12 months adjusted by age and BMI variation. Covariates appearing in the model are evaluated at the following values: $\%$ BMI baseline- 12 months $=34.32$, age $=41.66$

however, only RYGB patients showed a decrease in lumbar spine BMD [16]. Conversely, a meta-analysis conducted by Tian et al. found similar regional BMD declines at all analyzed sites post-LSG and RYGB [24]. Focusing only on LSG, the meta-analysis conducted by Jaruvongvanich et al. demonstrated a significant decrease in BMD at the hip and no significant change at the lumbar spine at 6-12 months after LSG [15].

The proximal femur was almost universally found to be the most afflicted site BMD-wise post-bariatric surgery, the most plausible explanations being mechanical unloading and a potential greater susceptibility of cortical bone [21, 25-28]. Since we evaluated regional BMD through wholebody DXA scans, we could not assess proximal femur BMD but, instead, recorded legs BMD. Interestingly, legs BMD did not differ significantly from baseline at 6 months postoperatively, only showing decline 12 months post-LSG. Looking into gender-oriented analysis, we found that men did display a slight decline in legs BMD 6 months postoperatively $(0.23 \pm 2.94 \%)$, but the final result was driven by the apparent increase in legs BMD in women (by $1.00 \pm 3.35 \%$ ). This is not the first report of regional BMD increase post-bariatric surgery, but previous studies have only described lumbar spine BMD increases [29, 30]. These findings support the dual role of obesity concerning the bone. Obesity is classically regarded as a protective factor for bone health, associated with lowered fracture risk [31, 32]. However, various authors have challenged this concept, as it seems more likely that obesity has positive effects on specific skeletal sites and negatively impacts others [33-35].

One of the most consistent correlations described in the literature is between BMD decline and the extent of weight loss [14, 21, 25]. In our study, BMD deterioration correlated positively with BMI decline only at 12 months 
and did not correlate to EWL at 6 months and 12 months postoperatively. Conversely, Geoffroy et al., in a study including 110 patients followed-up post-bariatric surgery, found a strong correlation between BMD decline and EWL [25]. Mechanical unloading represents the simplest explanation. However, the fact that bone loss also occurs in nonweight-bearing regions and advances in research has made it increasingly clear that the etiology of post-bariatric surgery bone loss is multifactorial. This is thought to involve changes in levels of nutrients, as well as in hormonal and cytokines milieu. Proposed factors include estrogen, insulin, IGF-1, cortisol, adipokines, incretins, calcium, vitamin D and parathormone [11, 14, 24, 36, 37]. Nevertheless, connections are not straightforward since postoperative changes in some are inconsistent, while others have an unclear impact on bone health [38, 39]. Peptide YY (PYY) is a molecule that has recently gained interest in light of its role in the gut-bone axis. This anorexigenic gut hormone shows significant increase following bariatric surgery and has been proven to be a negative regulator of bone mass and strength in animal studies [40-42]. In a recent study on patients undergoing RYGB, postoperative PYY increases negatively correlated with spine BMD and bone formation marker P1NP [43]. These effects are thought to be mediated through the variety of Y-receptors (Y1-5 in humans) that modulate both feeding behavior (Y1, Y5) and bone homeostasis (Y2, Y4) [44-46].

An important finding of our study was that men displayed a more significant decline in BMD 12 months postLSG compared with women at all sites, especially spine. This occurred although men and women displayed similar percentual BMI reductions at this point, and women had a significantly higher EWL. Therefore, simple mechanical unloading is an unlikely explanation for this difference. Instead, we hypothesize intricate contributions from the factors mentioned above may be responsible. Adipose tissue expansion leads to overexpression of aromatase, resulting in hyperestrogenism and subsequent decrease in pituitary LH, thus impairing testosterone secretion [47, 48]. Armamento-Villareal R. et al. evaluated hormonal changes in men with obesity after 12 months of lifestyle modification. They found that total and free estradiol levels drop with weight loss, but total and free testosterone levels show no improvement (possibly through a delay in LH unsuppression), and this may lead to worsening of age-related muscle and bone loss [49].

The main strength of our study, apart from including a large number of individuals, is patient distribution, which allowed valid comparisons between men, premenopausal, and postmenopausal women, respectively. This led to the key outcome, which is that 12 months post-LSG, men displayed greater BMD decline than premenopausal women, independently of weight loss and age. We could not identify a study on LSG providing a similar comparison. However, on a similarly divided cohort, the POUNDS-LOST diet trial revealed no BMD decline in men, while premenopausal women exhibited femoral neck BMD decline and postmenopausal women showed lumbar and femoral neck BMD decline [50]. Schafer et al. found that postmenopausal women had a more dramatic BMD decrease after RYGB, while BMD loss in men was less severe [51].

Our findings should be considered in the context of optimizing clinical care. If men are at greater risk for BMD loss after LSG, more careful evaluation, follow-up, and therapeutic intervention might be warranted. BMD trends over 12 months post-LSG also provide valuable information. Men seem to experience the most significant decline in BMD during the first 6 months. Therefore, this might represent the main therapeutical window for mitigating bone loss in male patients. Guideline recommendations regarding post-surgical medical and nutritional therapy are heterogeneous and non-gender oriented, but they all stress the need to ensure adequacy of calcium (1200-1500mg/day), vitamin D (3000UI/day, with a goal of $>30 \mathrm{ng} / \mathrm{mL}$ ), protein (a minimal of $60 \mathrm{~g} /$ day and up to $1.5 \mathrm{~g} / \mathrm{kg}$ ideal body weight per day), and physical exercise [52-54]. Since the loss of lean mass has been shown to positively correlate with the bone loss $[55,56]$, its preservation might also represent an intervention target. There is currently insufficient evidence to outline an optimal exercise regime to promote bone health. Generally, a combination of aerobic (preferably weight-bearing-e.g., walking, for a minimum of $150 \mathrm{~min}$, with a goal of 300 $\mathrm{min} /$ week), strength training (2-3 times/week), and flexibility exercises is recommended [52, 53, 57]. Although swimming is classically regarded as less effective [58], recent animal studies reveal beneficial skeletal outcomes [59-62]. This warrants future consideration, especially for the immediate perioperative setting when patients are still overweight or obese and might benefit from exercises that are less strenuous on articulations.

A limitation of this study is its short duration. However, evidence from longer-term research on bariatric surgery suggests the outcome does not improve with time, although weight loss mostly ceases after 12 months. Villarasa et al. revealed that postoperative decreases in BMD continue up to 3 years [56], while more recent studies have confirmed continued decline, albeit at a slower rate, up to $5[63,64]-7$ [65] years postoperatively.

Another limitation is the fact that we solely relied on DXA scans to assess bone density. Multiple studies have shown that the overlying fat can produce artifactual increases. They suggest quantitative computed tomography (QCT) as a more appropriate tool for evaluating bone mass in individuals with obesity, especially in the context of significant weight and body composition changes [66-68]. However, QCT is an 
expensive tool, unlikely to be implemented into routine clinical practice in the foreseeable future and DXA scans remain the mainstay of bone evaluation. Furthermore, Yu et al. conclude that, while on an individual level it might be challenging to interpret DXA evaluated changes in BMD with profound concomitant changes in body composition, group results are bound to be reliable [68].

\section{Conclusion}

Our study adds to the body of evidence that LSG negatively impacts BMD, stressing that bone health should represent one of the priorities of postoperative care. Moreover, the possibility that men suffer more profound bone loss after LSG warrants exploration and confirmation on larger cohorts since it is bound to modulate clinical practice.

\section{Declarations}

Conflict of Interest The authors declare that they have no conflict of interest.

Ethics and Consent All procedures performed in studies involving human participants were in accordance with the ethical standards of the institutional and/or national research committee and with the 1964 Helsinki declaration and its later amendments or comparable ethical standards.

Informed Consent Statement Informed consent was obtained from all individual participants included in the study.

Open Access This article is licensed under a Creative Commons Attribution 4.0 International License, which permits use, sharing, adaptation, distribution and reproduction in any medium or format, as long as you give appropriate credit to the original author(s) and the source, provide a link to the Creative Commons licence, and indicate if changes were made. The images or other third party material in this article are included in the article's Creative Commons licence, unless indicated otherwise in a credit line to the material. If material is not included in the article's Creative Commons licence and your intended use is not permitted by statutory regulation or exceeds the permitted use, you will need to obtain permission directly from the copyright holder. To view a copy of this licence, visit http://creativecommons.org/licenses/by/4.0/.

\section{References}

1. NCD Risk Factor Collaboration (NCD-RisC). Worldwide trends in body-mass index, underweight, overweight, and obesity from 1975 to 2016: a pooled analysis of 2416 population-based measurement studies in 128.9 million children, adolescents, and adults. Lancet. 2017;390:2627-42.

2. Roth J, Qiang X, Marbán SL, et al. The obesity pandemic: where have we been and where are we going? Obes Res. 2004;12(Suppl):2.

3. The International Federation for the Surgery of Obesity and Metabolic Disorders. 5th IFSO Global Registry Report 2019. Ifso.
2019. Available from: https://www.ifso.com/pdf/5th-ifso-globalregistry-report-september-2019.pdf.

4. Ozsoy Z, Demir E. Which bariatric procedure is the most popular in the world? A bibliometric comparison. Obes Surg United States. 2018;28:2339-52.

5. Eid GM, Brethauer S, Mattar SG, et al. Laparoscopic sleeve gastrectomy for super obese patients: forty-eight percent excess weight loss after 6 to 8 years with $93 \%$ follow-up. Ann Surg. 2012;256:262-5.

6. Reges $\mathrm{O}$, Greenland P, Dicker D, et al. Association of bariatric surgery using laparoscopic banding, roux-en-y gastric bypass, or laparoscopic sleeve gastrectomy vs usual care obesity management with all-cause mortality. JAMA J Am Med Assoc. 2018;319:279-90.

7. Singh P, Subramanian A, Adderley N, et al. Impact of bariatric surgery on cardiovascular outcomes and mortality: a populationbased cohort study. Br J Surg. 2020;107:432-42.

8. Douglas IJ, Bhaskaran K, Batterham RL, et al. Bariatric surgery in the United Kingdom: a cohort study of weight loss and clinical outcomes in routine clinical care. PLoS Med. 2015;12(12):e1001925.

9. Cottam D, Qureshi FG, Mattar SG, et al. Laparoscopic sleeve gastrectomy as an initial weight-loss procedure for high-risk patients with morbid obesity. Surg Endosc. 2006;20:859-63.

10. Gagnon C, Schafer AL. Bone health after bariatric surgery. JBMR Plus. 2018;2:121-33.

11. Saad R, Habli D, El Sabbagh R, et al. Bone health following bariatric surgery: an update. J Clin Densitom Elsevier Inc. 2019;23:165-81.

12. Johnson JM, Maher JW, Samuel I, et al. Effects of gastric bypass procedures on bone mineral density, calcium, parathyroid hormone, and vitamin D. J Gastrointest Surg Off J Soc Surg Aliment Tract United States. 2005;9:1101-6.

13. Ko B-J, Myung SK, Cho K-H, et al. Relationship between bariatric surgery and bone mineral density: a meta-analysis. Obes Surg. 2016;26:1414-21.

14. Liu C, Wu D, Zhang J-F, et al. Changes in bone metabolism in morbidly obese patients after bariatric surgery: a meta-analysis. Obes Surg. 2016;26:91-7.

15. Jaruvongvanich V, Vantanasiri K, Upala S, et al. Changes in bone mineral density and bone metabolism after sleeve gastrectomy: a systematic review and meta-analysis. Surg Obes Relat Dis. $2019 ; 15: 1252-60$.

16. Ieong $\mathrm{K}$, Ardila-Gatas $\mathrm{J}$, Yang $\mathrm{J}$, et al. Bone mineral density changes after bariatric surgery. Surg Endosc. 2021;35(8):4763-70.

17. Marshall D, Johnell O, Wedel H. Meta-analysis of how well measures of bone mineral density predict occurrence of osteoporotic fractures. Br Med J. 1996;312:1254-9.

18. Camacho PM, Petak SM, Binkley N, et al. American Association of Clinical Endocrinologists/American College of Endocrinology Clinical Practice Guidelines for the Diagnosis and Treatment of Postmenopausal Osteoporosis- 2020 update executive summary. Endocr Pract. 2020;26:564-70.

19. Buckley L, Guyatt G, Fink HA, et al. 2017 American College of rheumatology guideline for the prevention and treatment of glucocorticoid-induced osteoporosis. Arthritis Care Res. 2017;69:1095-110.

20. Mechanick JI, Youdim A, Jones DB, et al. Clinical practice guidelines for the perioperative nutritional, metabolic, and nonsurgical support of the bariatric surgery patient-2013 update: cosponsored by American Association of Clinical Endocrinologists, The Obesity Society, and American Society. Obesity (Silver Spring). 2013;21(Suppl 1):S1-27. 
21. Fleischer J, Stein EM, Bessler M, et al. The decline in hip bone density after gastric bypass surgery is associated with extent of weight loss. J Clin Endocrinol Metab. 2008;93:3735-40.

22. Carlin AM, Rao DS, Yager KM, et al. Treatment of vitamin D depletion after Roux-en-Y gastric bypass: a randomized prospective clinical trial. Surg Obes Relat Dis Off J Am Soc Bariatr Surg. 2009;5:444-9.

23. Vilarrasa N, de Gordejuela AGR, Gómez-Vaquero C, et al. Effect of bariatric surgery on bone mineral density: comparison of gastric bypass and sleeve gastrectomy. Obes Surg. 2013;23:2086-91.

24. Tian Z, Fan X-T, Li S-Z, et al. Changes in bone metabolism after sleeve gastrectomy versus gastric bypass: a meta-analysis. Obes Surg. 2020;30:77-86.

25. Geoffroy M, Charlot-Lambrecht I, Chrusciel J, et al. Impact of bariatric surgery on bone mineral density: observational study of 110 patients followed up in a specialized center for the treatment of obesity in France. Obes Surg. 2019;29:1765-72.

26. Stein EM, Silverberg SJ. Bone loss after bariatric surgery: Causes, consequences, and management. Lancet Diabetes Endocrinol. 2014;2:165-74.

27. Stein EM, Carrelli A, Young P, et al. Bariatric surgery results in cortical bone loss. J Clin Endocrinol Metab. 2013;98:541-9.

28. Maghrabi AH, Wolski K, Abood B, et al. Two-year outcomes on bone density and fracture incidence in patients with T2DM randomized to bariatric surgery versus intensive medical therapy. Obesity. 2015;23:2344-8.

29. Ruiz-Tovar J, Oller I, Priego P, et al. Short- and mid-term changes in bone mineral density after laparoscopic sleeve gastrectomy. Obes Surg. 2013;23:861-6.

30. Adamczyk P, Bužga M, Holéczy P, et al. Bone mineral density and body composition after laparoscopic sleeve gastrectomy in men: A short-term longitudinal study. Int J Surg. 2015;23:101-7.

31. De Laet C, Kanis JA, Odén A, et al. Body mass index as a predictor of fracture risk: a meta-analysis. Osteoporos Int. 2005;16:1330-8.

32. Kanis JA, McCloskey EV, Johansson H, et al. Development and use of FRAX in osteoporosis. Osteoporos Int. 2010;21(Suppl 2):S407-13.

33. Compston JE, Watts NB, Chapurlat R, et al. Obesity is not protective against fracture in postmenopausal women: GLOW. Am J Med. 2011;124:1043-50.

34. Prieto-Alhambra D, Premaor MO, Fina Avilés F, et al. The association between fracture and obesity is site-dependent: a population-based study in postmenopausal women. $\mathrm{J}$ bone Miner Res Off J Am Soc Bone Miner Res. 2012;27:294-300.

35. Tang X, Liu G, Kang J, et al. Obesity and risk of hip fracture in adults: a meta-analysis of prospective cohort studies. PLoS One. 2013;8:e55077.

36. Casimiro I, Sam S, Brady MJ. Endocrine implications of bariatric surgery: a review on the intersection between incretins, bone, and sex hormones. Physiol Rep. 2019;7:e14111.

37. Gregory NS. The effects of bariatric surgery on bone metabolism. Endocrinol Metab Clin North Am Elsevier Inc. 2017;46:105-16.

38. Hou J, He C, He W, et al. Obesity and bone health: a complex link. Front Cell Dev Biol. 2020;8:600181.

39. Malinici E, Sirbu A, Popa M, et al. Linking the brain and bone through fat. J Mind Med Sci. 2021;8:17-26.

40. Brzozowska MM, Tran T, Bliuc D, et al. Roux-en-Y gastric bypass and gastric sleeve surgery result in long term bone loss. Int J Obes. 2021;45:235-46.

41. McCarty TR, Jirapinyo P, Thompson CC. Effect of Sleeve Gastrectomy on Ghrelin, GLP-1, PYY, and GIP Gut Hormones: A Systematic Review and Meta-analysis. Ann Surg. 2020;272:72-80.
42. Leitch VD, Brassill MJ, Rahman S, et al. PYY is a negative regulator of bone mass and strength. Bone. 2019;127:427-35.

43. Kim TY, Shoback DM, Black DM, et al. Increases in PYY and uncoupling of bone turnover are associated with loss of bone mass after gastric bypass surgery. Bone. 2020;131:115115.

44. Sainsbury A, Baldock PA, Schwarzer C, et al. Synergistic effects of Y2 and Y4 receptors on adiposity and bone mass revealed in double knockout mice. Mol Cell Biol. 2003;23:5225-33.

45. Baldock PA, Sainsbury A, Couzens M, et al. Hypothalamic Y2 receptors regulate bone formation. J Clin Invest. 2002;109:915-21.

46. Utz AL, Lawson EA, Misra M, et al. Peptide YY (PYY) levels and bone mineral density (BMD) in women with anorexia nervosa. Bone. 2008;43:135-9.

47. Cohen PG. The hypogonadal-obesity cycle: role of aromatase in modulating the testosterone-estradiol shunt-a major factor in the genesis of morbid obesity. Med Hypotheses United States. 1999;52:49-51.

48. Schulster M, Bernie A, Ramasamy R. The role of estradiol in male reproductive function. Asian J Androl. 2016;18:435-40.

49. Armamento-Villareal R, Aguirre LE, Qualls C, et al. Effect of Lifestyle Intervention on the hormonal profile of frail, obese older men. J Nutr Health Aging. 2016;20:334-40.

50. Tirosh A, De Souza RJ, Sacks F, et al. Sex differences in the effects of weight loss diets on bone mineral density and body composition: POUNDS LOST trial. J Clin Endocrinol Metab. 2015;100:2463-71.

51. Schafer AL, Kazakia GJ, Vittinghoff E, et al. Effects of gastric bypass surgery on bone mass and microarchitecture occur early and particularly impact postmenopausal women. J Bone Miner Res. 2018;33:975-86.

52. Mechanick JI, Apovian C, Brethauer S, et al. Clinical Practice guidelines for the perioperative nutrition, metabolic, and nonsurgical support of patients undergoing bariatric procedures - 2019 Update: Cosponsored By American Association of Clinical Endocrinologists/American College of Endocrinology. Endocr Pract. 2019;25:1346-59.

53. Kim J, Nimeri A, Khorgami Z, et al. Metabolic bone changes after bariatric surgery: 2020 update, American Society for Metabolic and Bariatric Surgery Clinical Issues Committee position statement. Surg Obes Relat Dis. 2021;17:1-8.

54. Parrott J, Frank L, Rabena R, et al. American Society for Metabolic and Bariatric Surgery Integrated Health Nutritional Guidelines for the Surgical Weight Loss Patient 2016 Update: Micronutrients. Surg Obes Relat Dis Off J Am Soc Bariatr Surg. 2017; 13:727-41.

55. Costa TL, Paganotto M, Radominski RB, et al. Calcium metabolism, vitamin $\mathrm{D}$ and bone mineral density after bariatric surgery. Osteoporos Int. 2015;26:757-64.

56. Vilarrasa N, José PS, García I, et al. Evaluation of bone mineral density loss in morbidly obese women after gastric bypass: 3-year follow-up. Obes Surg. 2011;21:465-72.

57. Riebe D, Ehrman JK, Liguori G, et al editors. American College of Sports Medicine. ACSM's Guidelines for Exercise Testing and Prescription. 10th ed. Philadelphia: Lippincott Williams \& Wilkins; 2016.

58. Abrahin O, Rodrigues RP, Marçal AC, et al. Swimming and cycling do not cause positive effects on bone mineral density: a systematic review. Rev Bras Reumatol. 2016;56:345-51.

59. Kang YS, Kim JC, Kim JS, et al. Effects of swimming exercise on serum irisin and bone FNDC5 in rat models of high-fat dietinduced osteoporosis. J Sport Sci Med. 2019;18:596-603.

60. Falcai MJ, Zamarioli A, Okubo R, et al. The osteogenic effects of swimming, jumping, and vibration on the protection of bone quality from disuse bone loss. Scand J Med Sci Sports. $2015 ; 25: 390-7$. 
61. Ju YI, Sone T, Ohnaru K, et al. Effect of swimming exercise on three-dimensional trabecular bone microarchitecture in ovariectomized rats. J Appl Physiol. 2015;119(9):990-7.

62. Oh T, Tanaka S, Naka T, et al. Effects of high-intensity swimming training on the bones of ovariectomized rats. J Exerc Nutr Biochem. 2016;20:39-45.

63. Lindeman KG, Greenblatt LB, Rourke C, et al. Longitudinal 5-Year Evaluation of Bone Density and Microarchitecture After Roux-en-Y Gastric Bypass Surgery. J Clin Endocrinol Metab. 2018;103:4104-12.

64. Bühler J, Rast S, Beglinger C, et al. Long-Term Effects of Laparoscopic Sleeve Gastrectomy and Roux-en-Y Gastric Bypass on Body Composition and Bone Mass Density. Obes Facts. 2021;14:131-40.

65. Hansen S, Jørgensen NR, Hermann AP, et al. Continuous decline in bone mineral density and deterioration of bone microarchitecture 7 years after Roux-en-Y gastric bypass surgery. Eur J Endocrinol. 2020;182:303-11.

66. Javed F, Yu W, Thornton J, et al. Effect of fat on measurement of bone mineral density. Int J Body Compos Res. 2009;7:37-40.

67. Knapp KM, Welsman JR, Hopkins SJ, et al. Obesity Increases Precision Errors in Dual-Energy X-Ray Absorptiometry Measurements. J Clin Densitom. 2012;15:315-9.

68. Yu EW, Thomas BJ, Brown JK, et al. Simulated increases in body fat and errors in bone mineral density measurements by DXA and QCT. J Bone Miner Res. 2012;27:119-24.

Publisher's Note Springer Nature remains neutral with regard to jurisdictional claims in published maps and institutional affiliations. 